\title{
Effect of preservation time on the quality of frozen semen in indigenous
} rams

\author{
BBA Mahmuda*1, Azizunnesa², BF Zohara ${ }^{1}$, MGS Alam¹, FY Bari \\ ${ }^{1}$ Department of Surgery and Obstetrics, Bangladesh Agriculture University, Mymensingh 2202; ${ }^{2}$ Department of \\ Medicine and Surgery, Faculty of Veterinary Medicine, Chittagong Veterinary and Animal Science University, \\ Khulsi 4202, Chittagong, Bangladesh
}

\begin{abstract}
The study was carried out to observe the effects of preservation time on the quality of frozen semen of indigenous rams. Semen was collected using AV once a week from 4 rams. Tris based with $10 \%$ egg yolk and $7 \%$ glycerol extender was used to extend and freezing the semen. Fresh semen was evaluated for volume, density, mass motility and concentration, and mean values were observed as $0.8 \pm 0.2 \mathrm{ml}, 3.0 \pm 0.3,3.2 \pm 0.7,3.9 \pm 0.7 \times 10^{9} / \mathrm{ml}$, respectively. Significant difference $(p<0.05)$ was found for all the parameters among the rams. Mean values of motility, viability and normal morphology percentages were $83.3 \pm 4.3 \%, 88.2 \pm 4.4 \%, 84.2 \pm 3.5 \%$ in fresh semen while those of chilled semen at $4^{\mathrm{OC}}$ were $74.7 \pm 2.3,78.8 \pm 4.9$ and $79.2 \pm 2.9 \%$, respectively. For all the parameters, significant $(p<0.05)$ difference was found among the rams. Frozen sperm motility was observed after thawing at $39-40^{\circ} \mathrm{C}$ for 14-15 seconds. The mean motility, viability and normal morphology percentages after freezing for $24 \mathrm{hrs}, 7,15$ and 30 days of duration were $39.8 \pm 3.1,41.1 \pm 4.3,40.1 \pm 4.1$ and $39.4 \pm 2.9 \%$; 44.5 \pm 2.5 , $45.3 \pm 2.8,44.6 \pm 2.8$ and $43.9 \pm 2.8 \% ; 71.0 \pm 2.0,71.7 \pm 1.5,70.7 \pm 1.7$ and $70.3 \pm 1.8 \%$, respectively and values did not decrease significantly $(p>0.05)$ with the increasing time of preservation. Non significantly decrease of the semen quality with advance of preservation time indicates the suitability of the protocol used for freezing of indigenous ram semen in Bangladesh.
\end{abstract}

Key words: Frozen semen, preservation time, quality, ram

Bangladesh Animal Husbandry Association. All rights reserved.

Bang. J. Anim. Sci. 2015. 44 (1): 10-15

\section{Introduction}

The population of sheep in Bangladesh is about 3.12 million (DLS, 2014). During the last twelve years, sheep population increased 2.53 times, with annual growth rate of $5 \%$ in Bangladesh (BBS 2008). Most of sheep are non-descript type and sparsely distributed throughout the country with a relatively higher concentration in the coastal region of Noakhali enlarged with many char lands. Sheep populations in the northern part have been subjected to crossbreeding with exotic breeds mostly from imported Indian breeds (Rahman, 1989). Bangladeshi sheep are noted to be eminent for their ability to survive over a prolong period of drought, semi-starvation condition and disease resistant power. Sheep mortality is less than goat and less prone to extreme weather. Sheep are easy to handle and generally require little input and minimum amount of supplemental feeding.
Frozen semen enables to use good quality semen in long distance and for long time with good quality if it is maintained properly. The quality of frozen semen may vary on the maintenance of liquid nitrogen container holding semen in straws during storage. Five to eight percent glycerol and $10 \%$ egg yolk in tris-citric acid-fructose diluents yields $(54 \%)$ highest sperm motility in frozen-thawed ram semen (First et al. 1961; Ali et al. 1994). On research, in two-step dilution, equilibration at $5^{\circ} \mathrm{C}$ for 1.5 to 2 hours or over 2 hours yields the best thawing motility (Evans and Maxwell 1987). Most investigators thawed the ram frozen semen at $38-42{ }^{\circ} \mathrm{C}$ (Salamon and Maxwell 2000).

Sheep was neglected in the past in Bangladesh. Private entrepreneurs and government is trying to improve the husbandry and genetic merit of this species nowadays. Though Al of sheep is not practiced at this moment, it may be practiced

\footnotetext{
*Corresponding Author: akhibau87@gmail.com
} 
soon due to future demand. However, there is no report of production and cryo-preservation of frozen semen of ram in Bangladesh. The present study was, therefore, done to observe the effects of preservation time of indigenous ram semen to identify the suitability of protocol used for freezing.

\section{Materials and Methods}

The work was conducted at the Reproduction Laboratory of the Department of Surgery and Obstetrics, Faculty of Veterinary Science, Bangladesh Agricultural University during the period from November 2013-October 2014. Four rams were selected from parent flock of BASUSDA-PAULS funded research project. Age, body weight, and scrotal circumference of the ram were 4 years, 20 to $22 \mathrm{~kg}$ and 20 to $24 \mathrm{~cm}$, respectively. They were allowed 6 to 7 hours natural grazing. Each ram was fed approximately 300gm (Maize grit, wheat bran, wheat polish with salt) daily. The rams were dewormed routinely.

Stock solution for tris-fructose-citrate diluent was prepared by dissolving tris $(3.63 \mathrm{gm})$, fructose $(0.5 \mathrm{~g})$ and citric acid $(1.99 \mathrm{~g})$ in up to $76 \mathrm{ml}$ distilled water. The stock solution was preserved at $4-7^{\circ} \mathrm{C}$ for maximum 2 weeks. At the day of collection, fresh well churned egg yolk (10\%) and glycerol $(7 \%)$ were added with the stock solution to make $10 \mathrm{ml}$ of complete medium that was part B diluent and part A containing egg yolk without glycerol. In part of A diluent, distilled water of $7 \%$ was added instead of glycerol.

Semen was collected once in a week using AV method (Miller 1986). After collection, semen was kept at $37^{\circ} \mathrm{C}$ in water-bath until the media and reagents were added with it. The individual ejaculate was evaluated for volume, colour, density, mass activity, concentration, motility and morphology.

Two-step dilution method was used to freeze the semen in this experiment. Before semen collection, the final diluent was prepared and divided into two parts (part $\mathrm{A}$ and part $\mathrm{B}$ ) and placed in the water bath at $37^{\circ} \mathrm{C}$. After collection, individual ejaculate was diluted with calculated amount of diluent part $A$. One drop of semen was placed in a warm slide and the sperm motility was recorded. After that, diluted semen and diluent $B$ part were transferred to refrigerator for two hours. After two hours, calculated amount of diluent $B$ was poured into the previous diluted semen in three divided parts. Then, the semen was filled into the straws using micropipette. After filling, the straws were sealed by sealer. For equilibration, the sealed straws were placed in the refrigerator at $4{ }^{\circ} \mathrm{C}$ for further 2 hours. After two hours, the motility was recorded by using one drop of semen placed on the previously warmed slide under the microscope. Liquid nitrogen was poured in a special box where rack was placed in the box keeping a gap of $5-6 \mathrm{~cm}$ above the surface of the liquid nitrogen and kept for 30 minutes to stable bubbling of liquid nitrogen. The freezing was done in liquid nitrogen vapour (temperature $-80^{\circ} \mathrm{C}$ ) in a special box for 5-6 minutes. After 5-6 minutes, the straws were plunged into liquid nitrogen (temperature $196^{\circ} \mathrm{C}$ ). After that straws were transferred into cryocan at $-196^{\circ} \mathrm{C}$.

Before added extender, fresh semen was evaluated for volume, density, mass motility, concentration and observed motility, viability and normal morphology. The volume of the ejaculate was measured by reading the value on graduated tube and color and density were observed by naked eye. To evaluate the mass activity, a drop $(5 \mu l)$ of semen was placed on a pre-warmed slide $\left(37^{\circ} \mathrm{C}\right)$ without any cover slip and examined under microscope equipped with phase-contrast optics (10X). The mass activity was scored into 5 scales The wave motion was scored $0=$ no motility, 1 = few sperm with weak movement $(<20 \%), 2=$ some motile spermatozoa $(20-$ $40 \%$ ) without wave movement, 3 = slow wave movement (40-60\%) with motile spermatozoa, 4 $=$ rapid wave movement without whirlpool (60$80 \%$ ) with motile spermatozoa and $5=$ very rapid wave movement with clear whirlpools (>80\%) motile spermatozoa (Avdi 2004). The concentration of spermatozoa was determined by using hemocytometer. The concentration of sperm was measured in billion. For study of motility, a drop $(5 \mu \mathrm{l})$ of semen diluted at $1: 4$ ratio with tris was placed on a clean pre-warmed slide $\left(+37^{\circ} \mathrm{C}\right)$ and covered with a cover slip. The motility was determined by eye-estimation of the proportion of spermatozoa moving progressively 
straight forward at 40X. Viability was studied using eosin-nigrosin stain. A drop of sperm was placed on a glass slide. About $5 \mu \mathrm{l}$ eosin-nigrosin stain was added. The semen sample and stain were mixed with a clean stick, and a homogenous thin smear was prepared. The smear was observed at 40X. Live spermatozoa appear unstained and dead spermatozoa stained pink against a brownish purple background. At least 200 spermatozoa were examined from each smear. Morphology of sperm was studied using formal saline solution. A drop ( $5 \mu \mathrm{l})$ of semen was fixed with $2 \mathrm{ml}$ formal saline solution. The morphology was observed at high magnification (100X). At least 500 spermatozoa were individually examined. The percentages of normal morphology were recorded. After freezing, semen was thawed on $24 \mathrm{hrs} 7^{\text {th }}$ day, $15^{\text {th }}$ day and $30^{\text {th }}$ day of storage according to Salamon and Maxwell (2000). Thawed semen was evaluated for motility, viability and normal morphology.

All values relating to semen evaluation parameters were expressed as Mean \pm SD the statistical analyses were done using SPSS 17.0. One way analysis of variance was done to find out significant differences in semen parameters among the different duration of preservation.

\section{Results}

The mean values of semen parameters of fresh semen immediately after semen collection are shown in Table 1. The mean volume, density, mass activity, concentration, motility, viability and normal morphology of fresh semen were $0.8 \pm 0.2 \mathrm{ml}, 3.0 \pm 0.3$ (in the scale of 4 ) , 3.2 \pm 0.7 (in the scale of 5 ), $3.9 \pm 0.7 \times 10^{9} / \mathrm{ml}, 83.3 \pm 4.3 \%$, $88.2 \pm 4.4 \%$ ， $84.2 \pm 3.5 \%$, respectively. The volume, density, mass motility, concentration, motility, viability and normal morphology percentages of semen of ram number 3 was significantly lower $(p<0.05)$ than ram number 1 , 2 and 4.

The motility, viability and morphology percentages were observed immediately after semen collection (fresh) and while preserved at $4^{\circ} \mathrm{C}$ (chill semen) and $-196^{\circ} \mathrm{C}$ (frozen semen). The mean sperm motility, viability and normal morphology percentages fresh, chilled and frozen semen are shown in Table 2 . There was significant difference $(p<0.05)$ in motility, viability and normal morphology percentages for different types of semen (fresh, chilled and frozen) within rams. Ram no. 3 had significantly lower quality semen than other rams.

Table 1. Characteristics of indigenous ram semen (Mean \pm SD)

\begin{tabular}{|c|c|c|c|c|c|c|c|}
\hline Ram No. & Volume (ml) & Density (1-4) & Mass motility (1-5) & Conc. $\left(\times 10^{9}\right) / \mathrm{ml}$ & Motility (\%) & Viability (\%) & Morphology (\%) \\
\hline 1 & $0.8 \pm 0.2^{a}$ & $3.1 \pm 0.4^{a}$ & $3.4 \pm 0.9 \mathrm{a}$ & $4.2 \pm 0.7^{a}$ & $84.7 \pm 4.3^{a}$ & $89.1 \pm 4.5^{a}$ & $85.1 \pm 3.1^{a}$ \\
\hline 2 & $0.8 \pm 0.2^{a}$ & $3.2 \pm 0.2^{\mathrm{a}}$ & $3.5 \pm 1.0^{a}$ & $4.2 \pm 0.6^{a}$ & $84.9 \pm 4.0^{a}$ & $90.0 \pm 4.0^{a}$ & $86.3 \pm 3.7^{a}$ \\
\hline 3 & $0.6 \pm 1.0^{\mathrm{b}}$ & $2.8 \pm 0.3^{b}$ & $2.7 \pm 0.5^{b}$ & $3.1 \pm 0.4^{b}$ & $79.8 \pm 3.4^{b}$ & $84.5 \pm 3.7^{b}$ & $80.7 \pm 2.2^{b}$ \\
\hline 4 & $0.8 \pm 0.2^{a}$ & $3.1 \pm 0.3^{a}$ & $3.3 \pm 0.5^{a}$ & $4.0 \pm 0.5^{a}$ & $83.7 \pm 4.0^{a}$ & $89.1 \pm 4.1 a$ & $84.8 \pm 2.4 a$ \\
\hline Over-all mean & $0.8 \pm 0.2$ & $3.0 \pm 0.3$ & $3.2 \pm 0.7$ & $3.9 \pm 0.7$ & $83.3 \pm 4.3$ & $88.2 \pm 4.4$ & $84.2 \pm 3.5$ \\
\hline
\end{tabular}

Means with different superscript within the same column differed significantly $(p<0.05)$

Table 2. Comparison among fresh, chill and frozen semen with respect to motility, viability and normal morphology of spermatozoa (Mean \pm SD)

\begin{tabular}{|c|c|c|c|c|c|c|c|c|c|}
\hline \multirow{2}{*}{ Ram ID } & \multicolumn{3}{|c|}{ Motility \% } & \multicolumn{3}{|c|}{ Viability \% } & \multicolumn{3}{|c|}{ Normal morphology \% } \\
\hline & Fresh semen & Chill semen & Frozen semen & Fresh semen & Chill semen & Frozen semen & Fresh semen & Chill semen & Frozen semen \\
\hline 1 & $84.7 \pm 4.3^{\mathrm{aa}}$ & $75.6 \pm 5.1 \mathrm{c} \beta$ & $41.4 \pm 0.7 \mathrm{ev}$ & $89.1 \pm 4.5^{\mathrm{aa}}$ & $80.1 \pm 4.6^{\mathrm{c} \beta}$ & $45.4 \pm 0.7 \mathrm{er}$ & $85.1 \pm 3.1^{\text {aa }}$ & $80.3 \pm 2.3^{c \beta}$ & $71.2 \pm 0.8 \mathrm{er}$ \\
\hline 2 & $84.9 \pm 4.0 \mathrm{aa}$ & $76.1 \pm 3.4 \times \beta$ & $42.3 \pm 1.0 \mathrm{er}$ & $90.0 \pm 4.0^{\mathrm{aa}}$ & $81.0 \pm 4.1 \mathrm{c} \beta$ & $46.4 \pm 0.5^{\mathrm{er}}$ & $86.3 \pm 3.7 a a$ & $81.0 \pm 2.5^{c \beta}$ & $72.4 \pm 0.6 \mathrm{er}$ \\
\hline 3 & $79.8 \pm 3.4 b a$ & $71.3 \pm 2.1 \mathrm{~d} \beta$ & $35.5 \pm 0.7 \mathrm{fr}$ & $84.5 \pm 3.7 \mathrm{ba}$ & $74.9 \pm 2.6 \mathrm{~d} \beta$ & $40.5 \pm 0.6 \mathrm{fy}$ & $80.7 \pm 2.2^{b a}$ & $76.9 \pm 2.3 \mathrm{~d} \beta$ & $68.5 \pm 0.8 \mathrm{fy}$ \\
\hline 4 & $83.7 \pm 4.0$ aa & $75.7 \pm 5.7 c \beta$ & $40.7 \pm 1.2^{\mathrm{ev}}$ & $89.1 \pm 4.1^{\mathrm{aa}}$ & $79.3 \pm 5.8 с \beta$ & $46.1 \pm 0.6 \mathrm{er}$ & $84.8 \pm 2.4 \mathrm{aa}$ & $78.7 \pm 2.6 \subset \beta$ & $72.2 \pm 1.1 \mathrm{er}$ \\
\hline Mean & $83.3 \pm 4.3$ & $74.7 \pm 2.3$ & $40.1 \pm 3.1$ & $88.2 \pm 4.4$ & $78.8 \pm 4.9$ & $44.6 \pm 2.8$ & $84.2 \pm 3.5$ & $79.2 \pm 2.9$ & $70.9 \pm 1.7$ \\
\hline
\end{tabular}

$a b c d$, the mean values within the same column differs significantly $(p<0.05) ; \alpha \beta \gamma$, The mean values within the same row differs significantly $(p<0.05)$ 
Table 3. Effects of preservation time on post thaw sperm motility, viability and normal morphology $($ Mean $\pm \mathrm{SD})$

\begin{tabular}{|c|c|c|c|c|c|c|c|c|c|c|c|c|}
\hline \multirow{2}{*}{ Ram } & \multicolumn{4}{|c|}{ Motility \% } & \multicolumn{4}{|c|}{ Viability \% } & \multicolumn{2}{|c|}{ Normal morphology \% } & \multirow[b]{2}{*}{15 days } & \multirow[b]{2}{*}{30 days } \\
\hline & $24 \mathrm{hrs}$ & 7 days & 15 days & 30 days & $24 \mathrm{hrs}$ & 7 days & 15 days & 30 days & $24 \mathrm{hrs}$ & 7 days & & \\
\hline 1 & $40.9 \pm 3.8^{a a}$ & $42.4 \pm 3.7 \mathrm{ca}$ & $41.6 \pm 3.7 \mathrm{ea}$ & $40.8 \pm 3.99 a$ & $45.1 \pm 4.0^{a a}$ & $46.3 \pm 3.6^{c a}$ & $45.2 \pm 4.6^{\mathrm{ea}}$ & $44.8 \pm 4.99 a$ & $70.9 \pm 3.4$ aa & $72.4 \pm 2.7 \mathrm{ca}$ & $45.2 \pm 4.6^{\text {ea }}$ & $706+329 c$ \\
\hline 2 & $6 \pm 3.2^{2 \beta}$ & $43.1 \pm 3.1 \subset \beta$ & $42.5 \pm 3.0^{\mathrm{e} \beta}$ & $41.6 \pm 3.2^{g \beta}$ & $46.2 \pm 4.5^{\mathrm{a} \beta}$ & $47.0 \pm 4.3 c \beta$ & $46.4 \pm 3.9 \mathrm{e} \beta$ & $45.8 \pm 2.69 \beta$ & $72.4 \pm 3.8^{\mathrm{a} \beta}$ & $73.2 \pm 3.5^{c \beta}$ & $46.4 \pm 3.9 \mathrm{e} \beta$ & $71.8 \pm 2.59 \beta$ \\
\hline 3 & $0 \pm 1.2^{\text {by }}$ & $36.5 \pm 2.2^{\mathrm{dy}}$ & $35.5 \pm 3.1^{\mathrm{fv}}$ & $.1 \pm 1.2^{\mathrm{hy}}$ & $40.7 \pm 1.9^{\text {by }}$ & $41.2 \pm 2.7 \mathrm{dy}$ & $40.4 \pm 3.0^{f y}$ & $39.7 \pm 2.2^{\mathrm{hy}}$ & $68.2 \pm 4.0^{\text {by }}$ & $69.6 \pm 4.2^{\mathrm{dy}}$ & $40.4 \pm 3.0^{f y}$ & $67.9 \pm 3.8^{h}$ \\
\hline 4 & $40.8 \pm 4.6$ ат & $42.3 \pm 4.6 \mathrm{~cm}$ & $40.6 \pm 3.8 \mathrm{em}$ & $40.1 \pm 4.69 \pi$ & $45.8 \pm 5.3$ ат & $46.8 \pm 5.7 \mathrm{~cm}$ & $46.2 \pm 7.4 \mathrm{e} \pi$ & $45.4 \pm 2.29 \pi$ & $72.3 \pm 4.0$ ап & $71.6 \pm 4.1 \mathrm{~cm}$ & $46.2 \pm 7.4 \mathrm{e} \pi$ & $70.9 \pm 3.79 \pi$ \\
\hline Mean & $39.8 \pm 3.1$ & $41.1 \pm 4.3$ & $40.1 \pm 4.1$ & $39.4 \pm 2.9$ & $44.5 \pm 2.5$ & $45.3 \pm 2.8$ & $44.6 \pm 2.8$ & $43.9 \pm 2.8$ & $71.0 \pm 2.0$ & $71.7 \pm 1.5$ & $44.6 \pm 2.8$ & $70.3 \pm 1.8$ \\
\hline
\end{tabular}

$a b c d$, the mean values within the same column differs significantly $(p<0.05)$; $\alpha \beta \gamma \pi$, The mean values within the same row differs significantly $(p<0.05)$

The mean sperm motility, viability and normal morphology percentages following freezing at different duration is shown in Table 3. The motility, viability and normal morphology percentages were observed for $24 \mathrm{hrs}, 7,15$ and 30 days after preservation. Within each ram, the sperm motility, viability and normal morphology percentages did not significantly decrease $(p>0.05)$ following increasing the time of preservation. The motility, viability and normal morphology percentage of ram no. 3 at different duration of preservation time was significantly lower than other rams.

\section{Discussion}

In this study, semen was collected once in a week and did not show any significant difference among the rams with respect to volume, concentration and proportion of motile spermatozoa. The mean values of volume, density, mass motility, concentration of fresh semen were $0.8 \pm 0.2 \mathrm{ml}$, $3.0 \pm 0.4$ (in the scale of 4 ), $3.2 \pm 0.7$ (in the scale of 5), 2.5 - 5.0 billion $/ \mathrm{ml}$, respectively. These parameters are good to be used for breeding purpose. In published literature, the average volume of ram semen varied from $0.75 \pm 0.1$ to 1.4 $\pm 0.01 \mathrm{ml}$ (Guerrero et al. 2009; Pervage et al. 2009; Kulaksiz et al. 2012; Azizunnesa et al. 2014). The semen volume in the present work was comparatively lower than the published works. This could be due to variation in age of the ram, body condition, breed, season of the year, nutrition, and skill of the technician and the frequency of collection (Hafez and Hafez 2000). However, the density, mass motility, concentration of the present study was similar to other published literature (Gergatz 2007; Pervage et al. 2009; Kulaksiz et al. 2012).
The mean sperm motility was $83.3 \pm 4.3 \%$. This percentage is excellent to be used as fresh for Al or for preservation. Similar results were also observed in cited works (Pervage et al. 2009; Kulaksiz et al. 2012). Guerrero et al. (2009) found live sperm (viability) $90.2 \pm 3.8 \%$ in fresh semen. In the present study, the percentage of live spermatozoa percentages was $88.2 \pm 4.4 \%$.

The proportion of morphologically abnormal spermatozoa correlates negatively with fertility (Söderquist 1991; Shamsuddin et al. 1994). Nevertheless when both motility and normality of spermatozoa are used to grade the quality semen, the number of functionally normal spermatozoa appeared to be important determinant for fertility (Saacke et al. 2000). It is well documented that the fertilizing capacity of spermatozoa depends on the innate fertility of male as well as deposition of optimum number of morphologically spermatozoa into the uterus in time (Saacke et al. 2000). Large numbers of spermatozoa with abnormal tails were associated with reduced sperm motility (Söderquist 1991). In the present study, the percentage of morphologically normal spermatozoa percentages was $84.2 \pm 3.5 \%$. This normal percentage is acceptable for insemination. In other studies morphologically normal spermatozoa percentages was $94.0 \%$ (Hernandez et al. 2012).

In the present study, motility, viability normal morphology of chilled semen observed as $74.7 \pm 2.3 \%$, $78.8 \pm 4.9 \%$ and $79.2 \pm 2.9 \%$, respectively. This study was similar to other published literature (Pervage et al. 2009; Azizunnesa et al. 2014). 
In this study, two-step dilution and two hours equilibrium at $4^{\circ} \mathrm{C}$ for $2 \mathrm{hrs}$ after addition glycerol was maintained. In our study, for standardizing the thawing temperature $39-40^{\circ} \mathrm{C}$ for $10-12$ seconds of duration were selected. In order to maintain the benefit of a high rate of warming, ram semen frozen in straws has been thawed by most investigators at $38-42^{\circ} \mathrm{C}$ (Salamon and Maxwell 2000). Cabrera et al. (2011) conducted a research in ram where thawing was done at $38^{\circ} \mathrm{C}$ for 15 seconds and progressive individual motility was $56.8-62 \%$. The difference of the effect of thawing time on motility between present study and Cabrera et al. (2011) could be due to experimental differences due to purity of chemicals or skill of work.

Glycerol is the most commonly used protective substance in diluents for freezing ram semen. For semen frozen by the slow "conventional" method, and using mainly hypertonic diluents, most investigators found that the optimal glycerol concentration was within the range of $6-8 \%$; spermatozoa frozen rapidly by the pellet method survived best with 3-4\% glycerol in the diluent. Azizunnesa et al. (2014) observed best post thaw motility of ram spermatozoa in tris-citric acid-fructose diluent with $10 \%$ egg yolk and $7 \%$ glycerol during preservation. Five to eight percent glycerol yielded highest sperm motility (54\%) in frozen-thawed ram semen (First et al. 1961; Ali et al. 1994).

In present study, freeze semen motility, viability and normal morphology were significantly decreased than fresh and chill semen. Other workers pointed out that during freeze-thaw process about $50 \%$ of the initial population is lost (Hernandez et al 2012). In the present work, the mean value of motility percentages after $24 \mathrm{hrs}, 7,15,30$ days of preservation were $39.8 \pm 3.1,41.1 \pm 4.3,40.1 \pm 4.1$ and $39.4 \pm 2.9 \%$ and viability percentages $44.5 \pm 2.5,45.3 \pm 2.8,44.6 \pm 2.8$ and $43.9 \pm 2.8 \%$, respectively. In other research, with $6.5 \%$ glycerol with $10 \%$ egg yolk the progressive motility and viability percentages was $40.3 \pm 5.9 \%$ and $34.4 \pm 6.6$ after 3 month of preservation (Gurrero et al. 2009). In the present study sperm motility and viability percentages did not significantly decreased $(p>0.05)$ with the increasing time of preservation, indicating the use of suitable protocol for indigenous ram semen freezing. Although a relative high proportion (40$60 \%$ ) of ram spermatozoa preserve their motility after freeze thawing, only about $20-30 \%$ remain biologically un-damaged. Changes to the membrane of spermatozoa may not affect motility that is sperm morphology more affected than motility (Salamon and Maxwell 2000). The post thaw motility only indicates viability, but not fertilizing ability of sperm cell. In our study normal morphology percentages were $71.0 \pm 2.0$, $71.7 \pm 1.5,70.7 \pm 1.7$ and $70.3 \pm 1.8 \%$, respectively after 24 hrs, 7, 15 and 30 days of preservation duration. The normal morphology percentages did not significantly decreased ( $P>0.05$ ) with the increasing time of preservation. Hernandez et al. (2012) found normal sperm morphology percentages $79.5 \pm 5.7$ after 8 days of freezing. Different factors may affect the morphology of spermatozoa e.g. age of animal, environment and management, semen collection and processing, method of preservation and skill ness. To observe the duration effects on frozen semen, a semen bank was laid down in 1968 and fertility tests were conducted after $3,5,7,11,16$ and 27 years of storage. Cervical insemination was performed with high motility frozen semen for fertility test. The fertility results for semen stored for $3,5,7$, 11 years were not significantly different. A period of 27 years of storage had no effect on fertility, which shows that long-term frozen storage of ram semen is feasible and makes possible the banking of genetic resources in sheep breeding (Salamon and maxwell 2000).

\section{Conclusion}

The protocol used for freezing semen of indigenous ram was suitable as observed by nonsignificant decreased post thaw semen evaluation parameters with the progress of freezing time. However, attention must be paid about the limited number of rams used in the present study.

\section{Acknowledgements}

The authors are grateful to Bangladesh Academy of Science (BAS-USDA) and Department of Surgery and Obstetrics, Bangladesh Agricultural 
University, Mymensingh-2202 for financial and logistic support of this study.

\section{References}

Ali A, Ahmad KM, Gondal MA, Gondal KZ (1994). Effects of different levels of egg yolk and glycerol on cryopreservation of ram semen and conception rate ewes. Pakistan Veterinary Journal, 14: 163-167.

Azizunnesa, Zohara BF, Bari FY and Alam M (2014). Effects of Proportion of Egg Yolk and Preservation Time on Chilled Semen from Indigenous Rams. GSTF International Journal of Veterinary Science, 1: 18-26.

BBS (2010). Census of Agriculture 2008: Structure of Agricultural Holdings and Livestock Population Bangladesh-Volume 1. Bangladsh Bureau of Statistics, Dhaka. P. 711.

Cabrera VP, Ayulo L, Pantoja AC (2011). Effect of tris and citrate-quail egg yolk extenders on viability of ovine frozen semen in straws. Revistade-I nvestigacionesVeterinariasdel, 22: 105-113.

DLS (2014). Livestock statistics. Department of Livestock Services, Dhaka.

Evans G, Maxwell WMC (1987). Salmon's artificial insemination of sheep and goats. Bulterworths, Sydney. P. 107-141

First AL, Sevinge A, Hennernan HA (1961). Fertility of frozen and unfrozen ram semen. Journal of Animal Science, 20: 7984.

Gergatz E (2007). Artificial Insemination of Sheep. In Artificial insemination of domestic mammals. Edn. Pecsi T, Mezogazda Press, Budapest, Hungray. P. 335-367.

Guerrero VH, Huanca LW, Raymundo TF, Huerta OS, Ramos D (2009). Hypertonic extenders in the cryopreservation of ovine semen.
Revistade Investigaciones Veterinariasdel, 20: 41-46.

Hafez B, Hafez E (2000). Reproduction in Farm Animals.7th edition. Lippincott Williams and Wilkens, New York. P. 509.

Hernandez, Fernandez, Rodriguez (2012). Effect of cryopreservation of sheep semen related to its viability and acrosomal status. 34 : 78-83.

Kulaksiz R, Cebi C, Akcay E (2012). The effect of different extenders on the motility and morphology of ram sperm frozen or stored at 4 degrees C. Turkish Journal of Veterinary and Animal Sciences. 36: 177182.

Pervage S, Hassan MR, Ershaduzzaman M, Khandoker MAMY (2009). Preservation of liquid semen and artificial insemination in native sheep. Journal of Bangladesh Agricultural University. 7: 305-308

Rahman MM (1989). Sheep production and development in Bangladesh. In: Sheep production in Asia. Edn. Davendra C and Faylon PS. Proc. Workshop on Sheep Production in Asia. PACCARD, Los Bonas, Laguna, The Philippines. P. 81-95.

Saacke RG, Dalton J, Nadir S, Nebel RL, Babe J (2000). Relationship of seminal traits and insemination time to fertilization rate and embryo quality. Animal Reproduction Science. 61: 663-667.

Salamon S, Maxwell WMC (2000). Storage of ram semen. Animal Reproduction Science. 62: 77-111.

Shamsuddin M, Rodrihuez-Martinez H (1994). A simple, non-traumatic culture method for the selection of spermatozoa for in vitro in the bovine. Animal Reproduction Science. 36: $61-75$

Söderquist L (1991). Sperm characteristics and fertility in dairy Al bull. PhD Thesis, Swidish University of Agricultural Sciences, Upsala, Sweden. 